\title{
Judging Others in the Shadow of Suspicion ${ }^{1}$
}

\author{
Steven Fein ${ }^{2}$ \\ Williams College \\ James L. Hilton \\ University of Michigan
}

Previous research has found that when perceivers have reason to be suspicious of the motives underlying an actor's behavior, they are likely to draw inferences about the actor's true disposition that reflect a relatively sophisticated style of attributional processing. The present research was designed to examine some of the negative consequences that suspicion can have on perceivers' judgments. In each of the three studies reported, some subjects were made suspicious about the motives of an actor on the basis of contextual information surrounding the actor's behavior, rather than the behavior itself. Results of these studies suggest that, particularly when perceivers believe that the actions or motives of the actor could affect them, suspicion may cause perceivers to see the actor in a more negative light, even if the perceivers are not convinced that the actor's behavior was indeed affected by ulterior motives.

Although trust between strangers may be a rare commodity in these cynical times, research concerning social perception is brimming with studies that have demonstrated a remarkably robust tendency of perceivers that, on its surface, seems to reflect a rather naive and overly trusting nature. When individuals observe or learn about the behavior of a person about whom they have little or no prior information, they often draw inferences

\footnotetext{
'The authors thank Patrick Carver and Gilbert Fein for their assistance with the stimulus materials for Study 1, and Jessica Cross, Thomas Tomlinson, and Amy Elmore for their assistance with Studies 2 and 3.

${ }^{2}$ Address all correspondence to Steven Fein, Department of Psychology, Bronfman Science Center, Williams College, Williamstown, Massachusetts 01267.
} 
about the person that reflect the tendency to take the person's behavior at face value. Indeed, even when there are multiple plausible and sufficient explanations for the behavior, perceivers often infer that the behavior reflects the actor's true personality or attitudes, rather than hesitate to draw any inferences about the actor until they can rule out the other potential explanations.

This tendency to accept behavior at face value, which social psychologists have called the correspondence bias, the fundamental attribution error, and the overattribution effect (e.g., see Gilbert \& Jones, 1986) is quite robust. Even in studies designed to make the situational constraint faced by an actor extremely salient and quite obviously sufficient as an explanation for the actor's behavior (e.g., Allison, Mackie, Muller, \& Worth, 1993; Jones, 1979; Snyder \& Jones, 1974), subjects have tended to draw dispositional inferences about the actor that correspond to the behavior and that fail to take into sufficient account the situational factors that could have influenced the behavior.

This attribution bias is important because, in addition to its robustness, it can affect judgments across a wide variety of everyday situations. It can help provide a link between discrimination and stereotyping, for example, as perceivers ascribe negative dispositions to individuals of particular groups and fail to recognize the extent to which the behavior of these individuals has been constrained significantly by sociocultural obstacles and discrimination (e.g., Eagly, 1987; Word, Zanna, \& Cooper, 1974).

The primary goal of the present paper is to review and extend a recent line of research that examines the effects that suspicion has on perceivers' tendencies to fall prey to this robust bias. More specifically, Fein, Hilton, and Miller (1990), Fein (1991), and Hilton, Fein, and Miller (1993) have reported a series of studies demonstrating that suspicion of ulterior motives can be a powerful antidote to the correspondence bias. This work is reviewed briefly in this paper, and three new studies are reported that were designed to test further the effects of suspicion, particularly concerning the power of suspicion and the generalizability of its effects to contexts that are more involving to the subjects than were those found in previous research. More important, these studies also begin to examine some of the potential costs of suspicion.

\section{Suspicion and the Avoidance of the Correspondence Bias}

Fein et al. (1990) offered a working definition of suspicion as a state in which perceivers actively entertain multiple, plausibly rival, hypotheses about the motives or genuineness of a person's behavior. Moreover, sus- 
picion involves the belief that the actor's behavior may reflect a motive that the actor wants hidden from the target of his or her behavior. In their studies, subjects who learned contextual information about an actor's behavior that suggested (implicitly) that the behavior may have been influenced by ulterior motives were significantly less likely to make inferences reflecting the correspondence bias than were subjects who learned contextual information about strong situational constraint.

Subjects in one of these studies (Fein et al., 1990, Study 1), for example, read both a speech that argued either for or against a particular proposition as well as the context in which the author ostensibly wrote the speech. Half of the subjects read that the author was instructed to argue as he did as part of his job. That is, he was not given a choice about whether to argue for or against the proposition. The other half of the subjects read that the author was given the freedom to choose to argue either for or against the proposition, but they also read that the author's superior had strong feelings about the proposition. This information was designed to suggest to the subjects that the author may have been motivated to write his speech in the direction advocated by his superior in order to ingratiate. The speech that subjects read was consistent with the assignment given to the author in the no-choice conditions and with the attitude of the superior in the ulterior motives conditions. The results indicated that although the information about the constraint in the nochoice conditions was quite salient and strong, subjects in these conditions tended to infer that the author's true attitude corresponded to the attitude expressed in his speech. The inferences made by the subjects in the ulterior motives conditions, in contrast, were not affected by the direction argued in the speech.

As Fein et al. (1990) discussed, it is important to note several things about these results. First, on the basis of subjects' open-ended responses, it was clear that the subjects in the ulterior motives conditions did not conclude that the author was influenced by ulterior motives, but rather that he may have been. Second, it is not the case that the subjects in the nochoice conditions failed to recognize the situational constraint or that they dismissed it as too weak to account for the actor's behavior. When asked to estimate how many of 100 individuals in the author's position would have behaved as the author did, subjects in the no-choice conditions gave significantly higher estimates than did subjects in the ulterior motives conditions. Therefore, even though the former subjects recognized the strong situational constraint and believed that most individuals would have behaved as the author did, they tended to fall prey to the correspondence bias. The subjects in the ulterior motives conditions, on the other hand, recognized that the author had free choice, but they tended to suspend 
judgment about the author's true attitude because the plausibility that his behavior reflected ulterior motives rendered the behavior attributionally ambiguous.

\section{Explaining the Effects of Suspicion}

The finding that suspicion can help subjects avoid the correspondence bias was replicated across a number of studies, and is consistent with earlier research by Jones and his colleagues concerning ingratiation and strategic self-presentation (e.g., Jones, 1964; Jones, Davis, \& Gergen, 1961). But why does suspicion have this effect and what can it tell us about the nature of the inference process? Given that explanations based primarily on salience and normativeness (e.g., Kelley, 1973; Reeder, 1993; Reeder \& Brewer, 1979) are not supported by the results of Fein et al. (1990) and Fein (1991), other accounts must be offered.

The results reported in Fein et al. (1990), Hilton, Miller, Fein, and Darley (1990), Fein (1991), and Hilton et al. (1993) are consistent with the idea that suspicion triggers an unusually active and careful style of attributional thinking, and it this approach that helps suspicious perceivers avoid the correspondence bias. That is, once suspicious, perceivers seem unusually willing to devote cognitive resources to the question of why an actor behaved as he or she did, and they assess the relative plausibility (e.g., D. T. Miller, Turnbull, \& McFarland, 1989) of a variety of competing explanations. For example, Fein et al. (1990, Study 3) found that subjects who had been given reason to be suspicious of an actor were quite willing to make strong correspondent inferences from his behavior if they learned other information that rendered less plausible the explanation that the actor would be influenced greatly by ulterior motives (see also Hilton et al., 1993). Moreover, Fein (1991) found that suspicion about one actor led subjects to avoid the correspondence bias when making inferences about another actor whose behavior may have been affected by strong situational constraint, but they showed no unwillingness to make strong correspondent inferences about another actor when there was no particular reason to discount the actor's behavior.

\section{Suspicion, the Correspondence Bias, and Attributional Thinking}

The idea that the correspondence bias can be reduced by a more active, careful mind-set lends support to several current multiple-stage models of the dispositional inference process. These models divide the processes by which people infer dispositions from another's behavior into 
multiple stages that differ in terms of how much cognitive effort is required (e.g., Gilbert, Pelham, \& Krull, 1988; Jones, 1979; Trope, Cohen, \& Maoz, 1988). According to these models, perceivers tend to immediately and automatically draw a correspondent inference from the actor's behavior. This inference serves as an anchor from which perceivers adjust their later inferences. To the extent that perceivers devote cognitive resources to the latter stage of adjustment, they will take into account situational factors and discount or augment the initially correspondent inferences. However, because perceivers are rarely able or motivated to devote sufficient cognitive resources to the relatively arduous task of adjustment, the correspondence bias emerges.

\section{The Present Research}

Although suspicion can lead perceivers to avoid the correspondence bias when making inferences relevant to an actor's behavior, the attributional thinking that accompanies suspicion may come at some cost to both the perceiver and the actor. Specifically, the attributional thinking triggered by suspicion appears to cause perceivers to focus on the plausibility of the various potential explanations of an actor's behavior (e.g., Fein, 1991; Hilton et al., 1993). Because ulterior motives often offer such a plausible explanation for actors' behaviors, perceivers may be hard pressed to avoid allowing their suspicions about these motives to color their perceptions of the actors, particularly when the perceivers themselves could be affected by the actions and/or motives of the actor. For example, imagine a worker who observes his co-worker ask their boss if she would be interested in playing a weekly game of squash with her. Although it might be very plausible that the worker was genuinely interested in finding a squash partner and had heard that the boss enjoyed playing squash, it would also be highly plausible that the worker invited the boss in order to ingratiate, or to get some edge over the other workers. Although the worker who observes this invitation is likely to suspend judgment and draw no strong inference about the co-worker's true intentions, the very high plausibility that the coworker's behavior may have been obsequious or conniving may make the perceiver see her in a more negative light.

This possibility is likely to be particularly costly for the target of others' suspicions. Often through no fault of their own, actors may be the targets of others' suspicions because of the context in which their behavior occurred. In their studies on surveillance and trust, for example, Strickland and his colleagues (Strickland, 1958; Strickland, Barefoot, \& Hockenstein, 1976) and Kruglanski (1970) found that when subjects who played the roles 
of supervisors were put in a situation in which they monitored one worker more closely than another, they were more distrustful of the former worker even though the workers' actual behaviors did not differ. The supervisors' own behavior, therefore, made them less willing to trust the more closely monitored worker, presumably because their own behavior made this worker's performance more attributionally ambiguous. This ambiguity stems from the fact that the honest and dependable work performed by the more closely monitored worker could be attributed either to the worker's disposition or to the fact that the supervisor was present so frequently, whereas the same work performed by the less closely monitored worker could not be discounted as easily as a function of the surveillance. Moreover, Strickland (1958) and Strickland et al. (1976) found that the supervisors tended to continue to monitor more closely the former worker even when they had the opportunity to monitor both workers' subsequent performances equally. Given the plausibility of the explanation that the closely monitored worker's very honest and dependable work was the result of the supervisor's presence, such a worker would have a very difficult time earning the supervisor's trust.

The target of others' suspicions may be faced with a similar dilemma in more subtle contexts as well. The student who writes a wonderful speech that just happens to be consistent with his superior's own attitude, for example, may receive less than his fair share of accolades, particularly by his peers who may be competing for the good graces of their superiors, because of the high plausibility that the speech was written as it was simply to conform to the opinions of the author's superior and not because it reflected the author's true, impassioned beliefs. The problem is particularly daunting because the target of others' suspicions may often have an extremely difficult time dispelling the suspicions, given that suspicion of ulterior motives can render a wide range of behaviors attributionally ambiguous (e.g., simply writing a more impassioned speech will probably not eliminate suspicion). The negative effects of the perceivers' suspicions may emerge in other ways as well. For example, although the suspicious perceivers in the previous example may avoid any dispositional inference about the author's true attitude (i.e., they neither conclude that he does believe in what he said nor conclude that he wrote what he did in order to please his superior), they may be quick to call the actor's motives into question at some future time. Similarly, although they may refrain from making fairly specific dispositional inferences based on the content of a target's behavior, suspicious perceivers may feel less warmly toward the suspect and may be quite willing to entertain and express negative thoughts about him or her. 


\section{STUDY 1}

The studies reported in the present paper were designed to begin examining some of the costs of suspicion. In the first study, subjects' inferences about the actor's true attitude about an issue that was central to his behavior were assessed, as were their more general evaluations of the actor. It was predicted that suspicion would help subjects avoid falling prey to the correspondence bias in their inferences about the actor's true attitude but that it might cause perceivers' more general impression of the actor to be more negative. The specific methods used in the study differed from those used in previous studies on suspicion in two important ways. First, in previous studies the effects of suspicion have been tested against a manipulation that consists of varying which of two opposing positions an actor advocates in a speech or essay. In the present study, the position remained constant but the extremity of the arguments was varied (e.g., Jones, Worchel, Goethals, \& Grumet, 1971). The question addressed, then, was whether presenting subjects with information suggesting potential ulterior motives would cause subjects to discount the words of the actor even when those words were very strongly worded. In other words, would subjects be less likely to suspend their judgment of the actor if the actor did not merely advocate a particular position but rather argued strongly and aggressively for it?

Second, the subjects in the present study did not simply read about the behavior of some hypothetical actor and make inferences about him or her, as has been the case in numerous previous studies. Rather, these subjects believed that they were interacting with this actor. Moreover, the subjects in the suspicion conditions of this study had reason to suspect that the actor was trying to deceive them, rather than some hypothetical other person.

This latter difference was of particular interest for several reasons. The experimental task faced by the subjects was much more involving and complex than that used in the previously reported studies on suspicion. This complexity was created in part to test whether the effects of suspicion on perceivers' inferences would emerge when the perceivers are not removed, impassionate observers of an obviously hypothetical actor but instead are part of the actor's context (or so they were led to believe). More specifically, subjects in this study were given a relatively complex story which asked them to play the role of a member of some organization. The subjects were run in small groups, and they were led to believe that their performance in the study would be affected by other subjects. Subjects heard a presentation ostensibly made by another subject that argued either 
moderately or strongly in favor of a particular proposition. Half of these subjects had no reason to suspect the motives of this other subject, but half had reason to suspect that he may have argued for this proposition to sabotage their own performance in the study.

In addition to their inferences about the other subject's true attitude, the subjects were asked more general questions about him. It was predicted that in the involving context in which the subjects would be making their inferences in the present study, some negative effects of suspicion may be more likely to emerge. That is, suspicion about the other subject's true motives would cause subjects to refrain from making strong dispositional inferences about the other subject's true attitude, but that it would also make subjects more likely to see the other subject in a relatively negative light, such as in terms of how likeable the subjects would find him to be.

\section{Method}

\section{Subjects}

Subjects were 77 undergraduate students at the University of Michigan who participated in order to fulfill the research requirements of their Introductory Psychology course. Subjects were assigned randomly to the four conditions. The data from 2 of the 77 subjects were dropped from all analyses because they did not understand the instructions.

\section{Cover Story and Instructions}

Subjects were run in small groups, though they were always led to believe that five other subjects were present during their session. Upon arriving, they were placed in individual cubicles and told that the study was designed to investigate the effectiveness of various kinds of communication networks in organizations. The subjects were told that they would each be asked to play a role in a mock organization. The experimenter next explained that for the experiment to focus on communication networks and reduce the effects of nonverbal behaviors, the experiment required that all communication between subjects be through audiotaped messages that the subject would record and then send via the experimenter. The subjects then received a booklet that explained in some detail the structure and communication network of their organization.

Each subject was led to believe that the six subjects in their group were assigned different positions in the organization. In reality, however, each subject learned that he or she was "Subject No. 3" and that this meant 
they would be placed in a middle management position that would consist of being in charge of a committee comprising themselves and two subjects in lower-level positions. The committee's primary responsibility would be to prepare and give reports and presentations to the subjects in the upper-level positions. Each subject read, "You are . . . ultimately responsible for all reports that come out of your committee. The credit and blame go to you, and you alone. [The subjects in upper-level positions] have the power to reward and punish you. As head of the committee, you also have the power to reward and punish those beneath you."

When the subjects indicated that they understood their role, they were told that the first communication they would receive was a presentation from a particular subject in a lower-level position. (Hereafter, called the "presenter.") The subjects read that the presenter, a subordinate member of the committee of which they were in charge, was assigned to make a presentation about a proposal that several employees had made to upper management calling for the corporation to divest all of its holdings in South Africa. (At the time of the study, divestment was a relatively controversial topic on campus.) The subjects read the instructions apparently given to the presenter for this task. Included in these instructions was the following:

Subjects No. 5 and No. 6 [the upper-level positions] have very strong personal
opinions on this matter - they both feel the same way about the issue (either
strongly in favor of or against this proposal). However, rather than simply make a
decision about this proposal, they have asked Subject No. 3 to research and make
recommendations about this issue to them. Though Subject No, 3 will be solely
responsible for this presentation, he/she has given you the task of making the
presentation to him/her. Subject No. 3 will then make a presentation to Subjects
No. 5 and No. 6 based entirely on your presentation.

The subjects also read that the presenter was given a copy of the original divestment proposal and rationale, as well as a counterproposal filed by other employees who were opposed to the proposal.

\section{Manipulation of Suspicion}

In addition to the general context of the presenter's task, the subjects were also given some information about the roles that the two subjects in the lower-level positions on their committee were asked to play. It was explained to the subjects that they were given access to this information because of their superior position "on the corporate ladder," and they were also told that these lower-level subjects would not be aware that any other subject would have access to this information. This information included a description not only of the presenter's and the other subject's places in the organization but also of the goals and values they were instructed to adopt. The subjects read two descriptions - one for the presenter and one for 
the other subordinate - but they were not told which description corresponded to which subject.

In the no-suspicion conditions, both sets of information were quite innocuous. Ostensibly, one of the subordinates was asked to play the role of an intelligent, reliable but not terribly hard-working employee who would like to succeed in the organization but would not like a very high-pressure role. The other subordinate was asked to either play the same role or to play the role of an ambitious individual who was very motivated to rise up the corporate ladder by being very hard working and honest. Again, the subjects did not learn which role was given to which subordinate.

Subjects in the suspicion conditions read the same innocuous information about one of the subordinates (i.e., intelligent, reliable, but not terribly hard working), but they learned that the other subordinate's goal was either to try to rise up the corporate ladder by being very hard-working and honest or to try to rise by ruining Subject No. 3's [i.e., the actual subject's] career so that he or she could take over that position. The subjects did not learn which role was given to the presenter and which was given to the other subordinate. Moreover, the subjects read that both subordinates had been told how the upper-level subjects felt about the divestment proposal. The true subjects, however, did not learn what this attitude was. Thus, the subjects in the suspicion conditions were given reason to suspect that the presenter may have been motivated to make them look bad to the upper-level subjects. In addition, the subjects should have also recognized the power that the presenter had to hurt the subject's "career" by sabotaging the presentation, if he or she was so inclined.

\section{Manipulation of the Extremity of the Presentation}

Orthogonal to the manipulation of suspicion, the extremity of the position argued by the presenter was also varied. Half of the subjects heard a presentation that argued very strongly against divestment, and the other half heard a presentation that argued more moderately against divestment. The presentations were approximately equal in length and quality, but the former was much more one-sided and extreme in tone.

\section{Dependent Measures}

After they listened to the presenter's recorded presentation, the experimenter came into the subjects' rooms and said that from time to time they would be asked to complete questionnaires about themselves and their 
colleagues. The subjects were then given a sheet of questions about themselves and about the presenter. The subjects were asked to infer the presenter's true attitude toward divestment. They were asked to use a scale that ranged from strongly against divestment $(-5)$ to strongly in favor of divestment $(+5)$. The subjects were also asked to indicate how much they thought they would like the presenter as a person and colleague on a scale that ranged from strongly dislike $(-5)$ to strongly like $(+5)$, as well as to indicate how trustworthy they thought he was on a scale that ranged from not at all trustworthy (1) to very trustworthy (11).

After completing the questionnaire, the subjects were told that the study was over and were debriefed fully.

\section{Results}

\section{Inferences of the Presenter's True Attitude}

Subjects' inferences of the presenter's true attitude toward divestment were subjected to a 2 (Suspicion vs. No suspicion) $\times 2$ (Moderate Speech vs. Extreme Speech) analysis of variance (ANOVA). It was predicted that subjects would tend to suspend judgment of the presenter's true attitude when they had reason to suspect the presenter's motives, and that the extremity of the presentation would have a significant impact on the inferences only when the subjects had no reason to be suspicious. Consistent with predictions, a main effect for the manipulation of suspicion emerged, $F(1,71)=10.67, p<.002$, indicating that subjects were more likely to believe that the presenter was truly opposed to divestment in the no-suspicion conditions $(M=-1.66)$ than in the suspicion conditions $(M=0.00)$. A main effect also emerged for the manipulation of the presentation's extremity, $F(1,71)=6.88, p<.02$, indicating that subjects who heard the extreme presentation tended to infer that the presenter was more opposed to divestment $(M=-1.54)$ than did the subjects who heard the more moderate presentation $(M=-0.22)$. Although the interaction was not significant, $F(1,71)=2.40, p<.13$, the pattern was consistent with the hypotheses, as can be seen in Fig. 1. More critically, simple-effects analyses revealed that the manipulation of the extremity of the presentation had a very strong and significant effect on subjects' inferences in the no-suspicion conditions, $F(1,71)=9.20, p<.003$, and that the effect of this manipulation was eliminated in the suspicion conditions, $F(1,71)<1$. 


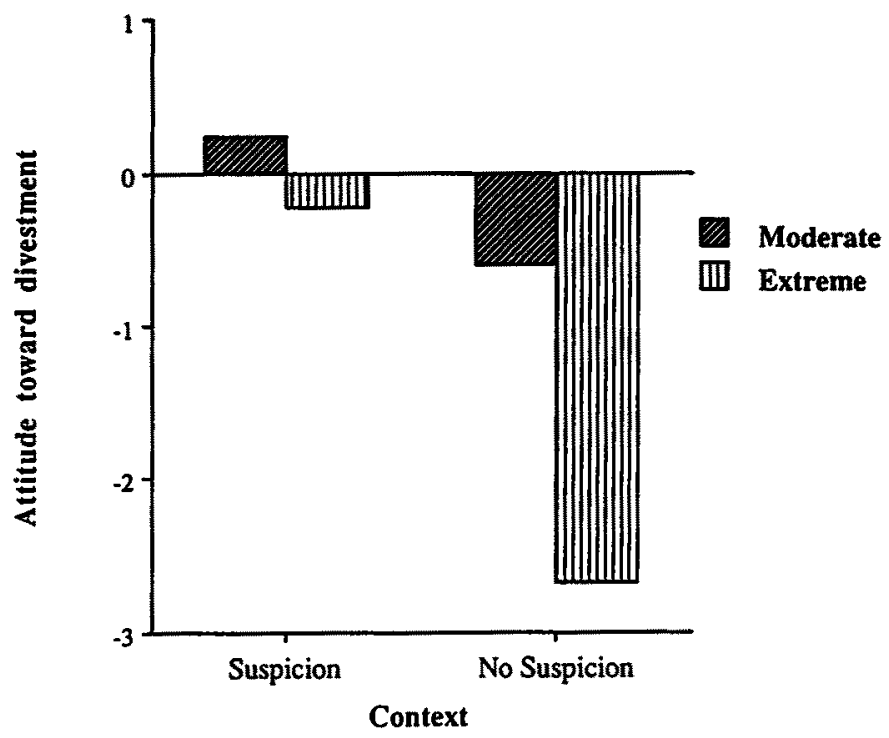

Fig. 1. Inferences about the presenter's true attitude toward divestment as a function of the extremity of the presentation and whether or not subjects had reason to suspect the presenter's motives.

\section{Evaluations of the Presenter}

Subjects' ratings of how much they thought they would like the presenter as a person and colleague were also subjected to the two-way ANOVA. As predicted, a significant main effect for the manipulation of suspicion emerged, $F(1,71)=8.15, p<.006$. Subjects in the suspicion conditions tended to think that they would like the presenter significantly less than did the subjects in the no-suspicion conditions $(M s=0.76$ vs. 2.15). Neither the main effect for the extremity of the presentation, nor the interaction, approached significance (both $F \mathrm{~s}<1$ ).

Subjects' evaluations of the presenter's trustworthiness were also analyzed. Once again, neither the main effect for manipulation of the extremity of the presentation, nor the interaction, approached significance (both $F \mathrm{~s}$ $<1)$. Similarly, although the means in the suspicion condition tended to be more negative $\left(M_{\text {suspicion }}=5.74\right.$ vs. $\left.M_{\text {no-suspicion }}=6.54\right)$, the difference was not significant, $F(1,71)=2.28, p<.14$. 


\section{Discussion}

Consistent with previous work on suspicion, the results of the first study suggest that when perceivers have reason to suspect the motives underlying a target's behavior, they refrain from inferring that the target's true attitude corresponds to the attitude that the target expressed in a particular situation. Subjects who had reason to suspect that the presenter may have argued for the position that he did to make them look bad did not infer that the presenter really was opposed to divestment, even if the presenter's arguments were very strongly worded. For these subjects, the extremity of the target's arguments was apparently not diagnostic of the presenter's true attitude. An extreme presentation could either mean that the presenter felt particularly strongly against divestment, or that the presenter wanted the subject to look especially bad to the subjects in the upper-level management roles. In the absence of suspicion, the extremity of the presentation retained its diagnostic value.

More centrally important for the present paper was the finding that subjects in the suspicion conditions disliked the presenter more than did the subjects in the no-suspicion conditions. Even though the subjects could not be sure if the presenter had any reason to behave in an insincere way, the possibility that he may have been motivated to sabotage the subject was enough to cause them to perceive him as less likeable. This finding suggests that if contextual information that a perceiver learns about a target person's behavior suggests that the target may have reason to try to dupe the perceiver and present himself or herself in an ingenuine way, the perceiver may hold this against the target and see him or her in a more negative light. Even though previous studies have shown that the type of manipulation that elicited suspicion in this study tends to cause subjects to suspend judgment about whether or not the target's behavior was affected by ulterior motives - rather than simply conclude that the target was indeed disingenuous - (e.g., Fein, 1991; Fein et al., 1990), and even though suspicious subjects in this study did not infer that the presenter was indeed very untrustworthy, the present results suggest that target of these suspicions may not escape unscathed. The high plausibility of situationally grounded ulterior motives may be enough to lead perceivers to see the target more negatively.

\section{STUDY 2}

In the suspicion conditions of Study 1 , subjects had reason to suspect not only that the presenter may have had ulterior motives but also that 
these ulterior motives could sufficiently account for the presenter's behavior. That is, subjects had reason to believe that virtually anyone in the presenter's position could have behaved as he did if he were motivated to do so - regardless of his true attitude (e.g., see Kelley, 1973; Reeder, 1993; Reeder \& Brewer, 1979). In the shadow of such suspicion, the target is confronted with a very daunting challenge. Behaviors that typically might serve to indicate clearly where they stand on an issue - such as arguing quite strongly for a particular position - are likely to lose their potency in the face of the attributional ambiguity.

There are other situations, however, in which the targets of suspicion are not so helpless. If perceivers suspect that a target is motivated to appear well versed in music, for example, they would have a difficult time discounting the target's behavior if that behavior involved answering quickly and expertly a variety of questions about Mozart's Minuet from the Divertimento in $D$, Eddie Lang's guitar work while playing under the pseudonym "Blind Willie Dunn," and bootleg recordings of Bruce Springsteen's benefit concerts for the Christic Institute. Reeder, Messick, and their colleagues (e.g., Messick \& Reeder, 1972, 1974; Reeder, Messick, \& Van Avermaet, 1977), as well as Hilton and Fein (Fein, 1991; see Hilton et al. 1993), have found that perceivers are likely to draw correspondent dispositional inferences from a target's behavior if that behavior reflects an ability that cannot be faked easily, even if the perceivers have reason to suspect that the target may have had ulterior motives to act as he or she did. Suspicious perceivers, therefore, do not become rigid in their hesitancy to take behavior at face value. But do they hold targets accountable for the suspicion in some other way?

Study 2 was designed to examine this issue by giving subjects a relatively weak negative expectancy about a target along with a relatively strong behavioral disconfirmation of that expectancy. Consistent with previous research (Fein, 1991; Hilton et al., 1993) it was predicted that suspicious subjects would be willing to draw inferences from the behavior that corresponded to the behavior, thereby disconfirming the negative expectancy. The primary question addressed in this study, however, was whether even in situations such as these - in which perceivers accept the target's behavior as genuine - suspicion might have some lingering effects on perceivers' feelings toward the target. Specifically, perceivers' suspicions about the target's motives may color their thoughts and feelings concerning the target - particularly when the target's behavior and potential ulterior motives are directed toward them (as in Study 1) - despite the fact that they are willing to draw correspondent inferences from his or her behavior.

To examine this prediction, an elaborate cover story was created so that each subject would think that he or she was interacting with another subject, and that some subjects would have reason to suspect the motives 
of their partner. Their partner's behavior, however, was constructed so that it would seem rather implausible that it could be accounted for by the ulterior motives alone. The degree to which subjects drew correspondent inferences from the target's behavior was assessed via interval-type scales. Subjects' negative feelings about the target were assessed with an openended measure. It was predicted that, although suspicious subjects would be willing to draw correspondent inferences from the target's behavior, they would be more likely than nonsuspicious subjects to indicate negative feelings about him on the open-ended, unrestricted measure.

\section{Method}

\section{Subjects}

Thirty undergraduate students at Williams College participated in this study for credit toward their Introductory Psychology course. Due to problems with the electronic mail system used during the study, the data from two of these subjects were dropped from all analyses.

\section{Preexperiment Instructions to Subjects}

When subjects were contacted by phone to arrange the time and location for the study, they were told that the study was about variables that affect the typical job interview. The subjects were instructed to ask a roommate, friend, or acquaintance to write a letter consisting of one or two paragraphs about one of the subject's best qualities and one of the subject's worst qualities. They were instructed to tell the writer not to mention any real names, to type the letter and put it in a sealed envelope, and to sign their name across the seal so that the contents of the letter would remain confidential. Finally, the subjects were told not to look at the letter at any point or to ask what was written in it.

\section{Cover Story and Instructions}

When subjects arrived at the laboratory, they were put into individual cubicles and were told that the study would involve simulating a job interview in order to enable the researchers to examine a variety of variables in the job interview situation. The subjects then read that some subjects in each session would be asked to play the role of an interviewer and others would be asked to play the role of a job candidate. The subjects had no 
way of knowing how many other subjects were being run in the same session. The experimenter indicated that there were several pairs of subjects being run simultaneously and that each subject would be paired randomly with another subject. In reality, only one or two subjects were run at a time, and each subject was told that he or she was randomly selected to be an interviewer. The subjects read that in this particular version of the study, all subjects would be put into individual cubicles so that the interviewer and job candidate would not be able to see or hear each other. The ostensible purpose of this was to isolate the content of what the candidate might say and partition out any "peripheral factors" such as physical appearance, tone of voice, and so forth. It was explained to the subjects that all communication between candidates and interviewers would be done via electronic mail.

The subjects read that another variable examined in the study concerned the structure of the interview. They were told that in this version of the study, interviewers would ask prepared questions, in the order in which the questions were presented for them, but that they would have some opportunities to ask their own "follow-up" questions for purposes of clarification.

Subjects next read that in order to simulate a real job interview situation, the experimenter was offering to the subjects who played the role of job candidates an incentive to try to do their best. The subjects read that all subjects who played the role of job candidates would be told that the three candidates during the course of the study who earned the most positive evaluations from the interviewers would each win $\$ 20$. The subjects read that the experimenter also wanted the subjects who played the role of job interviewers to take their roles seriously, but that it was more difficult to assess their performance. To measure their performance, it was alleged that the transcripts of their interviews would be given to two professors from a nearby Business School, and that the two interviewers whose assessments of their candidates were closest to those made by the professors would each win $\$ 10$.

\section{Creation of Negative Expectancy}

The subjects read that one aspect of real interviews is that the interviewer often reads letters of reference about the candidate before the interview. The experimenter then brought the letter concerning their partner (i.e., the job candidate) to the subject. The letter was ostensibly from someone who had just started to get to know the candidate during the semester. The first paragraph of the letter emphasized that the candidate was easy 
to get along with, down to earth, and able to handle the pressures and stresses of college better than most. The second paragraph went on to suggest that the candidate might not be well rounded and culturally literate, but it left open the strong possibility that this assessment may not have been valid and instead may reflect the particular limited interaction between the candidate and the letter writer (e.g., see Fein, 1991, Study 4).

After the subjects had read the letter, the experimenter came into the subjects' cubicles and explained that before they could conduct the job interview, they would need to know what the job entailed and what qualities they should be looking for in a candidate. They were given a profile entitled, "Ideal Qualifications for Job Candidates." In addition to emphasizing that the candidate must be intelligent, reliable, a good writer, and organized, this profile indicated that, "The job will require a great deal of interaction with many different people, so it is crucial that the person be very well rounded. Thus, the ideal candidate would be engaging and interesting, able to actively participate in conversations about a wide variety of topics. He or she should seem knowledgeable and well-rounded, able to offer educated opinions about numerous topics."

\section{Manipulation of suspicion}

The subjects were assigned randomly to either the high-suspicion or the low-suspicion condition. The independent variable was manipulated through information concerning the job candidate's awareness of both the letter of reference and the ideal candidate profile. For the subjects in the high-suspicion condition, the letter of reference was presented in an envelope that apparently had never been sealed. Moreover, when the experimenter came into the subjects' cubicles to give them the letter, she looked concerned. She asked the subjects if the person who had called them to schedule the experimental session had instructed them to tell their letter writer to seal and sign the envelope and not reveal its contents to them. When the subjects indicated that these were indeed the instructions given to them, the experimenter explained briefly that there apparently had been some confusion about this "by some of the subjects in the other rooms." The letter given to the subjects in the low-suspicion condition was in a signed and sealed envelope, and no mention of confusion about the instructions was made to the subjects. ${ }^{3}$

In addition to this variation which was designed to cause subjects in the high-suspicion condition to suspect that their job candidate may have read the letter, another variation concerned the candidate's awareness of

\footnotetext{
${ }^{3}$ The letters that the subjects brought to the lab were never read by anyone; rather, they were shredded at the conclusion of the experiment.
} 
the contents of the profile concerning the ideal qualifications for a job candidate. In the low-suspicion condition, the profile ended with the statement, "Because we did not want it to influence the candidate's interview responses, we have not given the candidate any information about the qualifications for the job." In the high-suspicion condition, in contrast, the profile stated, "Because we did not want it to influence the candidate's interview responses, we have not given the candidate all of this specific information. Rather, we have simply told candidates that they should be intelligent, responsible, and intellectually and culturally well rounded." This information was designed so that the subjects in the high-suspicion condition, who had reason to suspect that the candidate may have read that his letter called into question how intellectually and culturally well rounded he was, would suspect that the job candidate would be particularly motivated to try to appear to disconfirm sharply the negative expectancy about him so that he would have a chance to qualify for the job.

\section{The Interview}

After the subjects read the ideal qualifications for a job candidate, the experimenter explained the electronic mail system and how the interview would proceed. The subjects were given a list of 10 interview questions that they were supposed to ask, in the order presented. The experimenter also explained that at various points during the interview, she would interrupt the interview and ask the interviewer to complete an assessment of the candidate.

In reality, the experimenter was at a central computer and replied to the subjects' interview questions with prepared responses. The critical question was the third: "What kinds of extracurricular interests do you have?" The candidate's reply was designed to disconfirm the negative expectancy created by the letter writer about how well rounded and culturally literate he was. It emphasized the many intellectual and cultural interests that the candidate had and suggested that many of his acquaintances might not know that side of him. The reply was meant to be strong and detailed enough so that it would imply real knowledge about these interests. For the subjects who had reason to suspect the candidate's motives for trying to appear to be well versed in the arts and culture, the nature of the reply and the circumstances in which it was elicited should have caused them to infer that the motive alone could not account sufficiently for the candidate's interview performance. ${ }^{4}$

${ }^{4}$ It should be noted that the high-suspicion subjects did not learn any information that suggested that the candidate was not motivated to try to present himself in a misleading or self-enhancing way. Thus, they should have continued to be suspicious of the candidate, while 


\section{Dependent Measures}

After the candidate's reply to the third interview question was received by the subjects, the experimenter entered the subjects' cubicles and explained that this was one of those times in which she would interrupt the interview and ask the interviewer to evaluate the candidate. The subjects were given a brief questionnaire. In addition to a few filler items, the questions asked subjects to rate the candidate on 9-point scales concerning his knowledge and interest in culture, his ability to interact well with a variety of different people, and his well roundedness. The subjects were also asked to list any negative traits or qualities that they thought might be characteristic of the candidate, and they were given some blank space on the questionnaire in which to write any responses.

When subjects had completed these measures, they were told that the study was over, and they were debriefed fully. Two subjects were chosen at random to receive $\$ 10$.

\section{Results and Discussion}

The principle predictions were that the manipulation of suspicion would have weak or no effects on subjects' ratings of the candidate on dimensions relevant to the negative expectancy, but that the high-suspicion condition subjects would be more likely than the low-suspicion condition subjects to indicate negative concerns about the candidate on the openended measure. Consistent with the predictions, the results revealed that both high- and low-suspicion subjects were willing to infer that the candidate's personality corresponded to his interview performance on the dimensions that were relevant to the negative expectancy. As Table I indicates, on the ratings of the candidate's interest and knowledge in cultural activities, his ability to interact well with a variety of different people, and his well roundedness, subjects in the high-suspicion condition were as

\footnotetext{
inferring that the candidate's response to the critical interview question reflected his true interests. It should also be noted why the low-suspicion condition in this study is not called the "no-suspicion" condition. It was reasoned that some of the subjects in this condition would likely become somewhat suspicious when they noted that the letter called into question how well rounded the candidate was, that being well rounded was an important job qualification, and that the candidate's interview response emphasized that he was indeed quite well rounded. The quality and detail of the interview response, however, coupled with the apparent safeguards against the candidate becoming aware of the contents of the letter or the ideal profile, was designed so that it would render an ulterior motive based attribution relatively implausible.
} 
Table I. Mean Ratings of the Candidate and Percentage of Subjects Who Indicated Negative Qualities

\begin{tabular}{lccc}
\hline & High suspicion & Low suspicion & $t$ \\
\hline \multicolumn{4}{c}{ Mean ratings of the candidate on } \\
Cultural interests and knowledge & 5.67 & 6.00 & $<1.00$ \\
Ability to interact with variety of people & 7.00 & 7.62 & 1.59 \\
Well roundedness & 6.40 & 6.20 & $<1.00$ \\
& Open-ended responses & & \\
$\%$ who listed negative qualities & 60.00 & 23.08 & $3.88^{\circ}$ \\
\hline$\chi^{2} ; p<.05$. & & &
\end{tabular}

willing as the subjects in the low-suspicion condition to rate the candidate positively, suggesting that they did not dismiss his interview response as completely suspect. Thus, although they had reason to suspect that the candidate was aware of the negative expectancy and of the job qualifications and, therefore, may have been motivated to try to disconfirm this expectancy, there was no evidence that subjects in the high-suspicion condition held this against him when they rated him along dimensions relevant to the expectancy.

In contrast, when they filled out the open-ended measure, subjects in the high-suspicion condition were more likely to list negative qualities about the candidate. As can be seen in Table I, a majority of the subjects in the high-suspicion condition did volunteer a negative trait or quality about the candidate, whereas fewer than one fourth of the subjects in the low-suspicion condition did so. All but two of the qualities listed concerned subjects' suspicions about the candidate. The most frequent responses were, "trying to impress," "insincere," and responses indicating that the subjects suspected that he was saying things that he knew the interviewer was looking for.

These results suggest that when asked to make inferences that directly related to the expectancy, even the subjects who had good reason to suspect the motives of the candidate were willing to accept that the candidate's response did reflect his true interests. When not limited to making inferences simply about the dimensions relevant to the expectancy and interview 
response, however, the responses given by these subjects revealed that their suspicions about the candidate remained strong and rather salient.

\section{STUDY 3}

The subjects in the first two studies were presented with cover stories and experimental situations that were more detailed and involving than those found in most previous studies concerning suspicion. Study 3 was designed to examine more directly whether the degree of involvement that subjects have in the task can play an important role in determining the effects of suspicion. To this end, subjects in the study read information about three individuals who were candidates for a job and their task was to determine which candidate would be best suited for the job. Some of the subjects were given reason to be suspicious of the motives underlying the behavior of one of the candidates. For some of these subjects, the experimental task was designed to be involving and to make them feel accountable (e.g., Tetlock, 1985) and motivated to be accurate. For the other subjects who had reason to be suspicious, the experimental task was designed to be minimally involving.

For all subjects, the candidate about whom suspicions were sometimes raised was clearly the most qualified for the job along a series of dimensions (e.g., his intelligence). A set of questions addressed in this study, therefore, was whether suspicion about this candidate would cause subjects to reject him despite his otherwise impressive credentials, and whether this effect would vary as a function of the involvement of the subjects in their inferential task. One possibility was that their greater motivation for accuracy would make suspicious subjects in the high-involvement condition more likely to choose the candidate in question because of his obvious superiority to the other candidates. A second possibility was that their greater involvement in the task would make these subjects particularly wary of dismissing their suspicions. That is, they would be very hesitant to allow themselves to be duped by this candidate and thus might make a more conservative choice and choose a candidate whose credentials were not as strong but whose motives were not in question.

Finally, it is worth noting that the suspicion elicited in this study was not created by anything that the candidate did, but rather by the context of the candidate's behavior. To the extent that subjects in this study would reject this candidate because of their suspicions, the study would illustrate the very difficult position in which targets of suspicion may find themselves. 
Through no fault of the targets per se, suspicious perceivers may be unwilling to accept their behavior at face value.

\section{Method}

Subjects

Sixty-nine undergraduate students at Williams College participated in this study for credit toward their Introductory Psychology course.

\section{Procedure}

Subjects were run in groups of three. When all three subjects arrived at the laboratory, they were told that the study concerned the effects of different kinds of communication on group processes. The experimenter explained the cover story to the group, and then placed each subject into his or her own small room. The specific instructions for the subjects' tasks, and all stimulus materials and dependent measures, were presented to the subjects in a series of booklets. Subjects completed these materials individually.

\section{Design}

Each group of three subjects was assigned randomly to one of three conditions. Subjects in the suspicion/high-involvement condition and subjects in the no-suspicion/high-involvement condition were given a cover story and set of instructions that indicated that the study was a simulation of a complex group decision-making process, that their individual performances would be scrutinized by the other subjects, and that the decisions made by each of the subjects would affect the outcome (i.e., the chance to win money) of the other subjects in their group. The subjects in the former condition were given reason to be suspicious of a target individual, whereas the subjects in the latter condition were not. Subjects in the suspicion/low-involvement condition, like the subjects in the suspicion/high-involvement condition, were given reason to suspect the motives of a target person, but these subjects received a much simpler cover story which was designed to minimize subjects' feelings of accountability or outcome dependency. 


\section{Cover Story: High-Involvement Conditions}

Subjects in the two high-involvement conditions were told that their tasks would be to play the roles of executives in an organization, and that part of their jobs was to make important decisions regarding personnel. The three subjects in each session were told that they each would be asked to evaluate different candidates for various jobs and that their tasks were to recommend particular candidates to the other subjects in their group, as well as to evaluate the recommendations given them by these other subjects. The experimenter next explained that to encourage each group of subjects to do the best job they could, an award of $\$ 24$ would be given to the group of subjects in the study whose decisions were the most accurate. The experimenter asked the subjects to decide together on a name for their organization and explained that the name of the winning group would be announced in their introductory psychology class at the end of the semester.

The experimenter then gave the subjects a set of written instructions. These instructions emphasized information that was designed to make the subjects feel accountable to each other for their decisions. Through a cover story similar to that used in Study 2, the subjects were led to believe that their decisions would be compared against those made by a panel of experts who would have not only the information that the subjects would have but a more complete package of information about each candidate. The subjects' task, therefore, was to try to use the information that they did have about the candidates and recommend the best person for the job. The subjects learned that each of their decisions could earn or cost the group some amount of points; the better the decisions, the more points would be earned. They also read that the winning group would split the money evenly. Finally, the subjects read that at the end of each session, the experimenter would discuss with each group their individual decisions and what the optimal decisions were.

\section{Cover Story: Low-Involvement Condition}

Subjects in the suspicion/low-involvement condition saw the other subjects in their group only long enough for them all to hear the experimenter indicate that the study concerned the effects of different kinds of communication on group processes. The information presented to these subjects was designed to minimize any feelings of accountability or outcome dependency. These subjects were told nothing, therefore, of money to be won or what the other subjects were doing. There was no explicit mention of comparing their decisions with anyone else's, and the subjects were as- 
sured that all of their responses would be anonymous and confidential. They were told that they would read the materials, make their recommendations, and then be dismissed from the study.

\section{Job Description}

All subjects read a detailed description of the job ("Account Executive") for which they were to recommend the best candidate. The description concerned a number of qualities, such as intelligence, organization, reliability, and experience. Among the qualities emphasized were a number of factors concerning the ability to work well with others - to be a good "team player." Subjects in the two suspicion conditions read that "the job description was sent to each candidate a few days before their interviews so that they would have a more complete understanding of what the job entails." Subjects in the no-suspicion condition did not read anything about whether or not the candidates saw this description.

\section{Information About the Candidates}

All subjects received information about the same set of three candidates. For each candidate, the subjects received a resume, two letters of recommendation, and "edited transcripts" from the candidate's job interview for this position. The set of information about one of these three candidates, named "Jonathan Matthews," was designed to be much more impressive than were the sets of information about the other two candidates. Matthews had the best academic record by far, overwhelmingly positive letters of recommendation, the most astute interview responses, and previous jobs that made him the best prepared for the job. The other two candidates had average academic records, lukewarm letters, and less preparation.

In addition to all of the very positive information about Matthews, however, subjects in the two suspicion conditions were given some information about Matthews that was designed to elicit suspicion. In an otherwise glowing letter, one of the two letters recommending Matthews included the following:

If Mr. Matthews has an observable flaw, it is that he does not suffer fools gladly. That is, he does not tolerate work that has been handed to him by others which does not meet his standards, nor does he accept easily situations in which the work he has given to others does not progress in the way he had envisioned .... Thus, while this management style may be abrasive to some of the more sensitive people who will work under him, I think that his skills, enthusiasm, and high standards would serve as an inspiration to others, and I have no doubt that he would make a very effective, demanding, and ultimately very productive leader. 
Embedded in the job interview that subjects read later, Matthews claimed that he did indeed like to work with others, and that he greatly enjoyed being part of a team. Matthews did state, however, that he did not "like to work with others who, well, who don't carry their weight." Because the subjects in the suspicion conditions had read that all the candidates were aware of the qualities called for in the job description, which included an emphasis on the ability to engage in a great deal of teamwork and cooperation, and because they had also read that one of his letters indicated that he might have trouble working in groups, the interview response was designed so that subjects would be suspicious that Matthews was not entirely sincere in his statements about working with others as part of a team.

Subjects in the no-suspicion condition, in contrast, did not read that the candidates were aware of the job description, and the information in the letter that called into question Matthews' style of supervising others was deleted. All of the other information, however, was identical.

\section{Dependent Measure}

After the subjects had read all of the information, they were given a sheet of paper containing each of the three candidates' names. Information on the bottom of the page reminded subjects in the two high-involvement conditions that their recommendation would be shown to the other subjects. The subjects were asked to circle the name of the candidate whom they would recommend for the job.

After completing this measure, subjects were told that the study was over, and they were debriefed fully. One group of three subjects was chosen at random to receive $\$ 24$.

\section{Results and Discussion}

A chi-square test revealed that the independent variable had a significant effect on which candidates the subjects chose for the job, $\chi^{2}(4, N$ $=69)=18.92, p<.001$. Not surprisingly, subjects in the no-suspicion/highinvolvement condition - who never received the information suggesting that Matthews might have an interaction style ill-suited for job - were more likely to choose Matthews for the job (78.26\% of these subjects) than were subjects in the suspicion/high-involvement condition $(29.17 \%), \chi^{2}(2$, $N=47$ ) $=17.74, p<.001$.

This result suggests that the suspicions raised in the experiment were enough to cause subjects to discount the large body of other information that suggested clearly that Matthews was the most qualified candidate for 
the job in question. When the subjects believed that they would be accountable for their judgments, their suspicions about this candidate made them hesitate to take a chance on trusting him and so they tended to choose a less qualified candidate about whom they had no reason to distrust.

Taken from the perspective of the perceiver, this result is not very troubling. The combination of the information contained in the letter, the context of the interview, and the interview response made an ulterior motive explanation very plausible. In light of the suspicion that this raised, the subjects could not be sure if any of the information about the candidate could be trusted completely. Taken from the perspective of the target of suspicion, however, these results are particularly distressing. A lifetime of experiences that led to the positive set of information in the candidate's file was discounted in favor of a potentially uninformed remark in the midst of a very positive letter, taken together with the context of the candidate's behavior that the candidate himself did nothing to create.

Of greater interest to the thesis presented in this paper is the comparison between subjects in the suspicion/high-involvement condition and the suspicion/low-involvement condition. Consistent with the notion that greater involvement leads to greater wariness on the part of suspicious perceivers, suspicious subjects in the high-involvement condition were less likely to choose the target $(29.17 \%)$ than were suspicious subjects in the low-involvement condition $(54.45 \%), \chi^{2}(2, N=46)=5.76, p<.06$. This finding suggests that when perceivers have reason to suspect that they could be deceived by the actor and have to pay some price for this deception, their impressions of the actor may be especially likely to be affected by the plausibility of ulterior motive attributions.

\section{GENERAL DISCUSSION}

In each of the studies reported in this paper, the suspicions raised about the true motives or genuineness of the actor's behaviors stemmed from contextual information surrounding the behavior, rather than from the behavior itself. In Study 1, these suspicions resulted in suspended judgment about the extent to which the actor's true attitude corresponded to the attitude expressed in his speech, but they made the subjects see the actor as significantly less likeable. Although these subjects did not tend to conclude that the actor was indeed untrustworthy, the plausibility of the explanation that the actor was trying to deceive the subjects may have been great enough that the subjects tended to feel more negatively toward the actor. This pattern of results was in some ways even stronger in Study 2 . 
The results of this study suggest that the high plausibility that the actor may have had ulterior motives caused subjects to have negative concerns about the actor's sincerity even though the actor's behavior was strong and clear enough to convince subjects that the behavior could not be explained adequately by these ulterior motives. Thus, while they were making inferences about the actor that suggested that they took his behavior at face value, the subjects' distrust of the actor continued to emerge and influence their thoughts and feelings about him. Finally, the results of Study 3 illustrate that the negative effects of suspicion can emerge on dependent measures that were centrally important to the inferential task faced by the subjects, and they also suggest that these negative effects are more likely to emerge if perceivers feel particularly involved in and accountable for this inferential task.

\section{Other Negative Effects of Suspicion}

The negative effects of suspicion are by no means limited to those examined in the present research. The attributional thinking elicited by suspicion is likely to result in a variety of costs to the perceiver and to the target. For example, the relatively great amount of cognitive resources devoted to attributional analyses may tax perceivers' resources needed for other tasks. Interviewers who are dissecting a job candidate's interview responses to look for cues relevant to their suspicions, for example, may miss important information about the candidate on dimensions that are not relevant to the attributional task in which they are engaged. Moreover, in any interaction in which one of the interactants has reason to be suspicious of the motives of another, suspicion may have a strong effect on both the perceiver and the target of the suspicion. The cognitive resources that suspicious perceivers devote to attributional analyses may interfere with their ability to carry on the interaction smoothly and successfully (e.g., Gilbert \& Jones, 1986; Gilbert, Krull, \& Pelham, 1988; Neuberg, Judice, Virdin, \& Carrillo, 1993). Suspicious perceivers may not be able or care to hide their suspicions from the target of their suspicions. They may act in a more cold and distant way, perhaps guarding themselves from any self-disclosures that the target potentially could use to his or her advantage. This set of behaviors is likely to create a vicious circle in which the perceivers' suspicions lead the target to behave in strange ways, thus reinforcing the perceivers' suspicions.

Even when a target of suspicion is successful in behaving in such a way that cannot easily be discounted as reflective of ulterior motives, the target may continue to be under the shadow of suspicion for some time 
to come. Based on the thoughts that they indicated about the job candidate, it seems that the suspicious subjects in Study 2 of the present paper would have had a much lower threshold for becoming suspicious of the actor's subsequent behaviors than would the subjects who had not been given reason to be suspicious in the first place. More generally, it is possible that to the extent that their original suspicions are strong, perceivers are primed to perceive potential ulterior motives underlying an actor's future behaviors even if the original source of the suspicion proves groundless. This may be particularly damning for certain groups of people, such as individuals who are the targets of well-known and negative expectancies as a result of a stereotype or stigma. Because many perceivers are likely to suspect that these individuals would be particularly motivated to act in ways that appear to disconfirm these expectancies, the expectancy-inconsistent behaviors that these individuals may exhibit are likely to arouse suspicion (e.g., Fein, 1991; Hilton et al., 1993). Moreover, even when their specific behaviors cannot easily be discounted as misrepresentations of their true selves because of ulterior motives, the suspicion that these individuals do have such motives is likely to endure. Compounding the situation, research by Crocker, Major, and their colleagues has shown that stigmatized or stereotyped individuals are likely to have their own frequent suspicions about the perceivers' responses toward them (e.g., Crocker \& Major, 1989; Major \& Crocker, 1993), thus interfering further with the interactions between the perceivers and the targets.

\section{Moderating Factors}

The positive effects of suspicion on perceivers' inferences and attributional processing seem to be very robust across situations. That is, across a variety of contexts and behaviors, the research on suspicion has shown that the presence of even a small amount of information that suggests that an actor's behavior may have been influenced by ulterior motives can help subjects avoid the correspondence bias, and yet not inhibit their willingness to make correspondent inferences when there is no plausible reason for them to suspend their judgment of the actor. The negative consequences of suspicion as illustrated in the present research, however, are more likely to depend on a number of variables.

The results of the present study suggest that one such variable is the degree to which the perceivers feel that the actions and/or motives of an actor may affect them in some way. More generally, the relationship between the perceiver and the actor is likely to play a very important role. People who are in competition with an actor may be especially likely to 
be affected by the plausibility of ulterior motive explanations for the actor's behavior and thus see him or her in a very negative light, even if they are forced to admit that their original suspicions were ill-founded. In addition, partners in an intimate relationship may be particularly susceptible to the negative effects of suspicion that result in behaviors that tend to produce vicious circles and lowered thresholds for future suspicions (e.g., McCornack \& Levine, 1990).

Moreover, the type of relationship between the perceiver and actor may interact with the type of ulterior motive in question in determining the negative effects of suspicion. For example, if the ulterior motives in question concern ingratiation, perceivers who are the recipients of these actions may be less likely to see the actor in a negative light than would more distant observers (e.g., Jones, 1964). On the other hand, if the ulterior motives concern sabotage, rather than ingratiation, the perceptions of those who are more directly involved are likely to be more strongly tainted by their suspicions.

Other factors such as the goals of the perceiver (Hilton \& Darley, 1991; Neuberg, 1989), the perceiver's recent experiences (e.g., has the perceiver been deceived recently?), the norms of the situation, and whether the perceiver is alone or is part of a group may each influence how costly a perceiver's suspicions may be. In addition, a number of individual differences may play a role, such as differences on the dimensions of need for cognition (Cacioppo \& Petty, 1982), self-monitoring (Snyder, 1987), and need for closure (e.g., Kruglanski, Webster, \& Klem, 1993). Finally, there are likely to be cultural differences. For example, to the extent that the people in a culture acknowledge and appreciate the role of external, situational factors in determining individuals' behavior (e.g., J. Miller, 1984), recognizing potential ulterior motives may be much less likely to result in negative consequences for perceivers or actors.

\section{Conclusion}

It is somewhat ironic that one of the terms used to describe the correspondence bias is the overattribution effect. Although the term refers to the tendency to overattribute an actor's behavior to his or her disposition (and thus underattribute it to situational factors), the correspondence bias, according to the models outlined previously, reflects perceivers' tendency to engage in insufficient attributional thinking. In the years after the classic early social psychological models of the attribution process were first proposed by Heider, Jones, Kelley, and their colleagues (e.g., Heider, 1958; Jones \& Davis, 1965; Kelley, 1967, 1973), the metaphor of the perceiver 
as "naive scientist" determined to use the available information to assess causality and so make his or her world more predictable was replaced by the "cognitive miser" who would engage spontaneously in attributional deliberations only under relatively unusual conditions (e.g., Hastie, 1984; Weiner, 1985). These triggers of attributional thinking tend to be, at least in part, factors that perceivers bring to their perception of the actor, rather than factors inherent in the information about the actor and/or the context of the actor's behavior. The research on suspicion suggests that suspicion is another trigger of attributional thinking, but one that stems from the information itself.

The set of studies reported in the present paper, however, suggests that the heightened attributional thinking and attention to plausibility that is associated with suspicion can result in both positive and negative consequences. When perceivers have reason to distrust the genuineness or representativeness of an actor's behavior, they are likely to draw inferences about the actor's true attitudes that reflect a relatively sophisticated style of attributional processing. That is, they avoid the correspondence bias and suspend judgment about the actor on dimensions for which the behavior in question suggests multiple, and plausibly rival, dispositions. Their more general feelings or thoughts about the actor, however, may be tainted by their suspicion. Particularly when perceivers believe that the actions or motives of the actor could affect them, suspecting the motives of an actor may cause the perceivers to see the actor in a more negative light, even if they are not convinced that the actor's behavior was indeed affected by ulterior motives. Suspicion, therefore, can help perceivers avoid the biases that stem, in part, from a lack of attributional thinking, but in some circumstances it also may result in biased impressions of actors that result from too much thinking about the plausible ulterior-motive-based attributions.

\section{REFERENCES}

Allison, S. T., Mackie, D. M., Muller, M. M., \& Worth, L. T. (1993). Personality and Social Psychology Bulletin, 19, 151-157.

Cacioppo, J. T., \& Petty, R. E. (1982). The need for cognition. Journal of Personality and Social Psychology, 42, 116-131.

Crocker, J., \& Major, B. (1989). Social stigma and self-esteem: The self-protective properties of stigma. Psychological Review, 96, 608-630.

Eagly, A. H. (1987). Sex differences in social behavior: $A$ social-role interpretation. Hillsdale, NJ: Erlbaum.

Fein, S. (1991). The suspicious mind (Doctoral dissertation, University of Michigan, 1991). Dissertation Abstracts International, 52(7-B).

Fein, S., Hilton, J. L., \& Miller, D. T. (1990). Suspicion of ulterior motivation and the correspondence bias. Journal of Personality and Social Psychology, 58, 753-764. 
Gilbert, D. T., \& Jones, E. E. (1986). Perceiver-induced constraint: Interpretations of self-generated reality. Journal of Personality and Social Psychology, 50, 269-280.

Gilbert, D. T., Krull, D. S., \& Pelham, B. W. (1988). Of thoughts unspoken: Social inference and the self-regulation of behavior. Journal of Personality and Social Psychology, 55, 685-694.

Gilbert, D. T., Pelham, B. W., \& Krull, D. S. (1988). On cognitive busyness: When person perceivers meet persons perceived. Journal of Personality and Social Psychology, 54, 733-740.

Hastie, R. (1984). Causes and effects of causal attribution. Joumal of Personality and Social Psychology, 46, 44-56.

Heider, F. (1958). The psychology of interpersonal relations. New York: Wiley.

Hilton, J. L., \& Darley, J. M. (1991). The effects of interaction goals on person perception. In M. P. Zanna (Ed.), Advances in experimental social psychology, (Vol. 24, pp. 235-267). San Diego, CA: Academic Press.

Hilton, J. L., Fein, S., \& Miller, D. T. (1993). Suspicion and dispositional inference. Personality and Social Psychology Bulletin, 19, S01-512.

Hilton, J. L., Miller, D. T., Fein, S., \& Darley, J. M. (1990). When dispositional inferences are suspended: Diagnosing and calibrating traits. Revue Internationale de Psychologie Sociale, 4, 519-537.

Jones, E. E. (1964). Ingratiation: A social psychological analysis. New York: Appleton-Century-Crofts.

Jones, E. E. (1979). The rocky road from acts to dispositions. American Psychologist, 34, 107-117.

Jones, E. E., \& Davis, K. E. (1965). From acts to dispositions: The attribution process in person perception. In L. Berkowitz (Ed.), Advances in experimental social psychology (Vol. 2), pp. 283-330. New York: Academic Press.

Jones, E. E., Davis, K. E., \& Gergen, K. (1961). Role playing variations and their informational value for person perception. Journal of Abnormal and Social Psychology, 63, 302-310.

Jones, E. E., Worchel, S., Goethals, G. R., \& Grumet, J. (1971). Prior expectancy and behavioral extremity as determinants of attitude attribution. Journal of Experimental Social Psychology, 7, 59.80.

Kelley, H. H. (1967). Altribution theory in social psychology. Nebraska Symposium on Motivation, 15, 192-238.

Kelley, H. H. (1973). The processes of causal attribution. American Psychologist, 28, 107-128.

Kruglanski, A. W. (1970). Attributing trustworthiness in supervisor-worker relations. Joumal of Experimental Social Psychology, 6, 214-232.

Kruglanski, A. W., Webster, D. M., \& Klem, A. (1993). Motivated resistance and openness to persuasion in the presence or absence of prior information. Journal of Personality and Social Psychology, 65, 861-876.

Major, B., \& Crocker, J. (1993). Social stigma: The consequences of attributional ambiguity. In D. M. Mackie \& D. L. Hamilton (Eds.), Affect, cognition, and stereotyping: Interactive processes in group perception (pp. 345-370). San Diego: Academic Press.

McCornack, S. A. \& Levine, T. R. (1990). When lies are uncovered: Emotional and relational outcomes of discovered deception. Communication Monographs, 57, 119-138.

Messick, D. M., \& Reeder, G. D. (1972). Perceived motivation, role variations, and the attribution of personal characteristics. Journal of Experimental Social Psychology, 8, $482-491$.

Messick, D. M., \& Reeder, G. D. (1974). Roles, occupations, behaviors, and attributions. Journal of Experimental Social Psychology, 10, 126-132.

Miller, D. T., Turnbull, W., \& McFarland, C. (1989). When a coincidence is suspicious: The role of mental simulation. Journal of Personality and Social Psychology, 57, 581-589.

Miller, J. (1984). Culture and the development of everyday social explanation. Journal of Personality and Social Psychology, 46, 961-978.

Neuberg, S. L. (1989). The goal of forming accurate impressions during social interactions: Attenuating the impact of negative expectancies. Journal of Personality and Social Psychology, 56, 374-386. 
Neuberg, S. L., Judice, T. N., Virdin, L. M., \& Carrillo, M. A. (1993). Perceiver self-presentational goals as moderators of expectancy influences: Ingratiation and the disconfirmation of negative expectancies. Joumal of Personality and Social Psychology, 64, 409-420.

Reeder, G. D. (1993). Trait-behavior relations and dispositional inference. Personality and Social Psychology Bulletin, 19, 586-593.

Reeder, G. D., \& Brewer, M. B. (1979). A schematic model of dispositional attribution in interpersonal perception. Psychological Review, 86, 61-79.

Reeder, G. D., Messick, D. M., \& Van Avermaet, E. (1977). Dimensional asymmetry in attributional inference. Joumal of Experimental Social Psychology, 13, 46-57.

Snyder, M. (1987). Public appearances/private realities: The psychology of self-monitoring. New York: Freeman.

Snyder, M. L., \& Jones, E. E. (1974). Attitude attribution when behavior is constrained. Journal of Experimental Social Psychology, 10, 585-600.

Strickland, L. H. (1958). Surveillance and trust. Journal of Personality, 26, 200-215.

Strickland, L. H., Barefoot, J. C., \& Hockenstein, P. (1976). Monitoring behavior in the surveillance and trust paradigm. Representative Research in Social Psychology, 7, 51-57.

Tetlock, P. E. (1985). Accountability: A social check on the fundamental attribution error. Social Psychology Quanterly, 48, 227-236.

Trope, Y., Cohen, O., \& MaOz, Y. (1988). The perceptual and inferential effects of situational inducements on dispositional attribution. Journal of Personality and Social Psychology, 55, 165-177.

Weiner, B. (1985). "Spontaneous" causal thinking. Psychological Bulletin, 97, 74-84.

Word, C. O., Zanna, M. P., \& Cooper, J. (1974). The nonverbal mediation of self-fulfilling prophecies in interracial interaction. Journal of Experimental Social Psychology, 10, 109-120. 